\title{
Effects of hydrocarbon generation, basal heat flow and sediment compaction on overpressure development: a numerical study
}

\author{
Jennifer Hansom and Ming-Kuo Lee \\ Department of Geology and Geography, Auburn University, Auburn, Alabama 36849, USA \\ (e-mail:leeming@auburn.edu)
}

\begin{abstract}
This study outlines numerical experiments to investigate the effects of hydrocarbon generation, basal heat flow and sediment compaction on overpressure development in evolving sedimentary basins. The model integrates predicted groundwater flow and temperature and pressure distribution with thermal maturation simulations. The programme uses the Arrhenius kinetic model to simulate the kerogen-oil or oil-gas conversion processes. Such conversion processes result in an increase in fluid volume and overpressure development since oil and gas generated are less dense than their precursors. The model integrates an equation of state to calculate gas densities for the $\mathrm{CH}_{4}-\mathrm{CO}_{2}-\mathrm{H}_{2} \mathrm{O}$ system over a wide temperaturepressure (T-P) range expected in sedimentary basins; this approach allows for prediction of the rate of pore volume increases and fluid pressure changes due to gas generation. Sample calculations of compaction of kerogen-rich shales in the Delaware Basin shed light on the magnitudes of overpressures created by hydrocarbon generation from the Late Pennsylvanian to Middle Permian. Oil generation can cause excess pore pressure (c. $425 \mathrm{~atm}$ ) up to $c .40 \%$ of that generated by compaction only (c. $300 \mathrm{~atm})$. Oil and $\mathrm{CH}_{4}$ gas generation together yield the maximum excess pressure (c. $750 \mathrm{~atm})$ up to about $150 \%$ of that generated by compaction only. There is much greater pore pressure build-up from oil to $\mathrm{CH}_{4}$ conversion $(c .325 \mathrm{~atm})$ than oil to $\mathrm{CO}_{2}$ conversion $(c .75 \mathrm{~atm})$ because density of $\mathrm{CH}_{4}$ gas is less than that of $\mathrm{CO}_{2}$ under the same $\mathrm{P}$ and $\mathrm{T}$ conditions. Sensitivity analyses also show that lower activation energy and higher pre-exponential factor lead to faster thermal cracking that allows oil or gas to reach peak generation earlier. Moreover, a basin experiencing a high heat flow throughout the burial history reaches hydrocarbon generation and overpressure development earlier. Calculation results also show that the oil and gas windows become deeper as the sedimentation rate increases. Thus, a basin experiencing high sedimentation rates would exhibit higher levels of thermal maturity and excess pore pressure over the deeper section. This also implies that greater overpressure may be expected at shallower depths in a basin with relatively low sedimentation rates. The modelling results demonstrate that kinetic parameters, basal heat flow and sedimentation rates all influence the timing, duration and depth of oil and gas generation, which in turn, profoundly affects the spatial and temporal distribution of overpressure.
\end{abstract}

KEYWORDS: bydrocarbon generation, overpressure, fluid migration, compaction

\section{INTRODUCTION}

Many low-permeability sedimentary strata are characterized by elevated pore fluid pressures that are much greater than the hydrostatic pressures. There is considerable interest in understanding the origin of overpressures in sedimentary basins because the presence of geopressured fluids represents a major hazard for well blowout during drilling. Overpressures can influence basin fluid migration strongly and thus play an important role in creating ore deposits and localizing petroleum reservoirs (e.g. Bethke 1989; Lee \& Williams 2000).

Various dynamic mechanisms have been proposed for generating overpressures in sedimentary basins, including

Petroleum Geoscience, Vol. 11 2005, pp. 353-360 disequilibrium compaction (Bethke 1986; Shi \& Wang 1986), tectonic collision (Ge \& Garven 1992), aquathermal expansion (Sharp 1983), clay dehydration (Burst 1969), gravity flow (Toth 1962; Lee \& Bethke 1994; Wolf et al. 2005), gas capillary seals (Revil et al. 1998; Lee \& Deming 2002) and hydrocarbon generation (Luo \& Vasseur 1996; Lee \& Williams 2000). In old, mature basins abnormal pressure cannot be maintained by dynamic processes like compaction, aquathermal expansion or clay mineral transformation. Hydrocarbon generation, which involves the conversion of solid kerogen into liquid oil and then into gas, is considered to be an important geopressuring mechanism in tectonically stable basins. The role of 
hydrocarbon generation on overpressuring has been explored quantitatively by several workers (Barker 1990; Forbes et al. 1992; Luo \& Vasseur 1996). Most of these studies used simplified fluid state models or assumed constant fluid density to calculate the volume increases during kerogen-oil or oil-gas conversion. In this study, the equation of state (EOS) for the $\mathrm{CH}_{4}-\mathrm{CO}_{2}-\mathrm{H}_{2} \mathrm{O}$ gas system (Duan et al. 1992) over a wide temperature-pressure ( $\mathrm{T}-\mathrm{P})$ range was incorporated into a transient hydrology model Basin2 (Bethke et al. 1993) that calculates flow velocities, temperature and pressure distribution in evolving sedimentary basins. The EOS is chosen on the basis of its ability to predict accurately the variations in gas density within the desired temperature and pressure range in sedimentary basins.

Sediment compaction and thermal maturation of oil and gas during the deposition of a shale sediment column is simulated. Special attention is given to (1) the relative contribution of disequilibrium compaction, oil generation and gas generation on overpressure build-up; and (2) the effects of kinetic parameters, basal heat flow and sedimentation rates on hydrocarbon generation and overpressure development. The purpose of constructing numerical models is to quantify the timing, duration and magnitude of overpressure development in various geological conditions. In field applications, the numerical model is applied to investigate how hydrocarbon generation helps maintain overpressure in the tectonically stable Delaware Basin, where there has been insignificant sedimentation and compaction for the last $250 \mathrm{Ma}$. The results of this modelling study stress the importance of considering oil and gas generation in evaluating the evolution of overpressure and fluid migration in sedimentary basins.

\section{NUMERICAL MODEL OF OVERPRESSURING BY GAS GENERATION}

\section{Model of hydrocarbon generation}

Oil and gas generation may contribute to the development of significant overpressure in sedimentary basins. The overpressuring processes can be simulated by integrating thermal maturation models with hydrological models that predict temperature and pressure distribution in evolving sedimentary basins. The Arrhenius model (e.g. Lewan 1985; Tissot et al. 1987) was used to quantify the oil or gas generated as a fraction of the source bed's capability, calculating the rate constant $k$ (in $\mathrm{h}^{-1}$ ) using a simple equation:

$$
k=A_{g} e^{-E_{A} / R T_{K}}
$$

Here $A_{\mathrm{g}}$ is the pre-exponential factor $\left(\mathrm{h}^{-1}\right), E_{\mathrm{A}}$ is the activation energy $\left(\mathrm{KJ} \mathrm{mol}^{-1}\right), \quad R$ is the gas constant (8.31432 $\mathrm{J} \mathrm{K}^{-1} \mathrm{~mol}^{-1}$ ) and $T_{\mathrm{k}}$ is the absolute temperature $(\mathrm{K})$. Integrating the first-order rate law obtains the extent of gas generation:

$$
\frac{d X_{g}}{d t}=k\left(1-X_{g}\right)
$$

expressed as a fraction $X_{\mathrm{g}}$ (dimensionless, ranging from 0 to 1 ) of the oil's capacity for generating gas. According to the Arrhenius equation, the extent of gas generation depends on the activation energy $E_{\mathrm{A}}$ and the pre-exponential factor $A_{\mathrm{g}}$. Kinetic parameters differ among the various types of kerogen or oils found in source rocks (Quigley et al. 1987; Braun \& Burnham 1992; Pepper \& Corvi 1995; Dieckmann et al. 1998). Such differences indicate that the timing, duration and rate of hydrocarbon generation (and thus overpressure generation) is not the same for all source rocks.

The conversion of oil to gas $\left(\mathrm{CH}_{4}\right.$ or $\left.\mathrm{CO}_{2}\right)$ will result in an increase in fluid volume because the liquid oil is generally denser than the gas. The rate of volume generation $q_{c}\left(\mathrm{~h}^{-1}\right)$ per unit porous media is given by:

$$
q_{c}=\frac{\rho_{\mathrm{o}}}{\rho_{\mathrm{g}}} \frac{d X_{\mathrm{g}}}{d t}
$$

here $\rho_{\mathrm{o}}$ and $\rho_{\mathrm{g}}$ are the density of oil and gas, respectively. Gas generation will destroy liquid oil, which counteracts gas generation in producing excess fluid volume. The rate of oil destruction per unit porous media is:

$$
q_{r}=\frac{d X_{\mathrm{g}}}{d t}
$$

Combining two effects, the net volume change of fluid phases per unit porous media is given by

$$
q_{\text {oil }- \text { gas }}=\frac{d X_{\mathrm{g}}}{d t}\left(\frac{\rho_{\mathrm{o}}}{\rho_{\mathrm{g}}}-1\right)
$$

Kerogen-oil conversion processes can be simulated using a similar set of equations (see Bredehoeft et al. 1994; Lee \& Williams 2000). In the fluid flow model, the effects of oil and gas generation are included as fluid source terms $\left(q_{\text {kerogen }}-\right.$ oil and $q_{\text {oil }}$-gas $)$ in the governing equation:

$$
\begin{aligned}
\varphi \beta \frac{\partial P}{\partial t}=\frac{\partial}{\partial x}\left[\frac{k_{x}}{\mu}\left(\frac{\partial P}{\partial x}\right)\right]+\frac{\partial}{\partial z}\left[\frac{k_{z}}{\mu}\left(\frac{\partial P}{\partial z}-\rho g\right)\right]- \\
\frac{1}{1-\varphi} \frac{\partial \varphi}{\partial t}+\varphi \alpha \frac{\partial T}{\partial t}+q_{\text {kerogen }}-\text { oil } \\
+q_{\text {oil }}-\text { gas }
\end{aligned}
$$

Equation (6), modified from Bethke (1989), can be used to calculate the net pressure change resulting from various hydrologic and geological processes. The first two terms on the right-hand side of equation (6) describe the migration of fluid away from the source beds. The third term describes compaction (pore collapse) and the fourth term accounts for aquathermal expansion. The last two terms account for oil and gas generation. The flow away from the source beds acts to dissipate the pressure build-up in rocks. Therefore, the net pressure change depends on (1) rate of compaction (sedimentation), (2) rate of aquathermal expansion, (3) rate of hydrocarbon generation and (4) the permeability of the reservoir and confining rocks.

\section{Gas density calculations: an equation-of-state (EOS) approach}

The gas volume or gas density over a wide T-P range $\left(0-1000^{\circ} \mathrm{C}\right.$ and $\left.0-8000 \mathrm{~atm}\right)$ can be evaluated by the equation of state (Duan et al. 1992):

$$
\begin{aligned}
\frac{P_{\mathrm{r}} V_{\mathrm{r}}}{T_{\mathrm{r}}}=1+\frac{B}{V_{\mathrm{r}}}+\frac{C}{V_{\mathrm{r}}^{2}}+\frac{D}{V_{\mathrm{r}}^{4}}+\frac{E}{V_{\mathrm{r}}^{5}}+ & \\
& \frac{F}{V_{\mathrm{r}}^{2}}\left(\beta+\frac{\gamma}{V_{\mathrm{r}}^{2}}\right) \exp \left(-\frac{\gamma}{V_{\mathrm{r}}^{2}}\right)
\end{aligned}
$$

where

$$
B=a_{1}+\frac{a_{2}}{T_{\mathrm{r}}^{2}}+\frac{a_{3}}{T_{\mathrm{r}}^{3}}
$$




$$
\begin{gathered}
C=a_{4}+\frac{a_{5}}{T_{\mathrm{r}}^{2}}+\frac{a_{6}}{T_{\mathrm{r}}^{3}} \\
D=a_{7}+\frac{a_{8}}{T_{\mathrm{r}}^{2}}+\frac{a_{9}}{T_{\mathrm{r}}^{3}} \\
E=a_{10}+\frac{a_{11}}{T_{\mathrm{r}}^{2}}+\frac{a_{12}}{T_{\mathrm{r}}^{3}} \\
F=\frac{a}{T_{\mathrm{r}}^{3}} \\
V_{\mathrm{c}}=\frac{R T_{\mathrm{c}}}{P_{\mathrm{c}}} \\
T_{\mathrm{r}}=\frac{T}{T_{\mathrm{c}}} \\
P_{\mathrm{r}}=\frac{P}{P_{\mathrm{c}}} \\
V_{\mathrm{r}}=\frac{V}{V_{\mathrm{c}}}
\end{gathered}
$$

Empirical parameters $a_{1}-a_{12}, \alpha, \beta, \gamma, T_{\mathrm{c}}$, and $P_{\mathrm{c}}$ in EOS for gases $\mathrm{CO}_{2}, \mathrm{CH}_{4}$ and $\mathrm{H}_{2} \mathrm{O}$ are compiled by Duan et al. (1992). $T_{\mathrm{c}}$ is the critical temperature above which a gas cannot be liquefied by an increase of pressure. $P_{c}$ is the least applied pressure required at the critical temperature to liquefy a gas. $V_{\mathrm{c}}$ is the volume of a fixed mass of fluid at $T_{\mathrm{c}}$ and $P_{\mathrm{c}}$. Given calculated $T$ and $P$ in a basin's strata, $T_{\mathrm{r}}$ and $P_{\mathrm{r}}$ can be calculated from equations (10)- (11). The reduced volume $V_{\mathrm{r}}$ in the non-linear equation (7) can be solved by the well-known Newton method (Carnahan et al. 1969). In this method, one first makes an initial guess $V_{\mathrm{r}}^{(0)}$ as the solution for

$$
\begin{aligned}
f\left(V_{\mathrm{r}}\right)=1-\frac{P_{\mathrm{r}} V_{\mathrm{r}}}{T_{\mathrm{r}}}+\frac{B}{V_{\mathrm{r}}}+\frac{C}{V_{\mathrm{r}}^{2}}+\frac{D}{V_{\mathrm{r}}^{4}}+\frac{E}{V_{\mathrm{r}}^{5}}+ \\
\\
\frac{F}{V_{\mathrm{r}}^{2}}\left(\beta+\frac{\gamma}{V_{\mathrm{r}}^{2}}\right) \exp \left(-\frac{\gamma}{V_{\mathrm{r}}^{2}}\right)=0
\end{aligned}
$$

The deviation from the right-hand side of the equation (i.e. $0)$ is the residual

$$
R\left(V_{\mathrm{r}}^{(0)}\right)=f\left(V_{\mathrm{r}}^{(0)}\right)
$$

The Newton's method iteratively improves the solution $V_{\mathrm{r}}$ by projecting the tangent to the residual function $R$ to zero. The tangent or the slope of the residual function of EOS is

$$
\begin{array}{r}
f^{\prime}\left(V_{\mathrm{r}}\right)=-\frac{P_{\mathrm{r}}}{T_{\mathrm{r}}}-\frac{B}{V_{\mathrm{r}}^{2}}-\frac{2 C}{V_{\mathrm{r}}^{3}}-\frac{4 D}{V_{\mathrm{r}}^{5}}-\frac{5 E}{V_{\mathrm{r}}^{6}}+\frac{F}{V_{\mathrm{r}}^{2}}\left(\beta+\frac{\gamma}{V_{\mathrm{r}}^{2}}\right) \\
\left(2 \frac{\gamma}{V_{\mathrm{r}}^{3}}\right) \exp \left(-\frac{\gamma}{V_{\mathrm{r}}^{2}}\right)+\frac{F}{V_{\mathrm{r}}^{2}}\left(-2 \frac{\gamma}{V_{\mathrm{r}}^{3}}\right) \exp \left(-\frac{\gamma}{V_{\mathrm{r}}^{2}}\right)+ \\
\left(-2 \frac{F}{V_{\mathrm{r}}^{3}}\right)\left(\beta+\frac{\gamma}{V_{\mathrm{r}}^{2}}\right) \exp \left(-\frac{\gamma}{V_{\mathrm{r}}^{2}}\right)
\end{array}
$$

The correction $\Delta V_{\mathrm{r}}$ at any iteration $q$ is

$$
\Delta V_{\mathrm{r}}^{q}=-\frac{R\left(V_{\mathrm{r}}^{q}\right)}{f\left(V_{\mathrm{r}}^{q}\right)}
$$
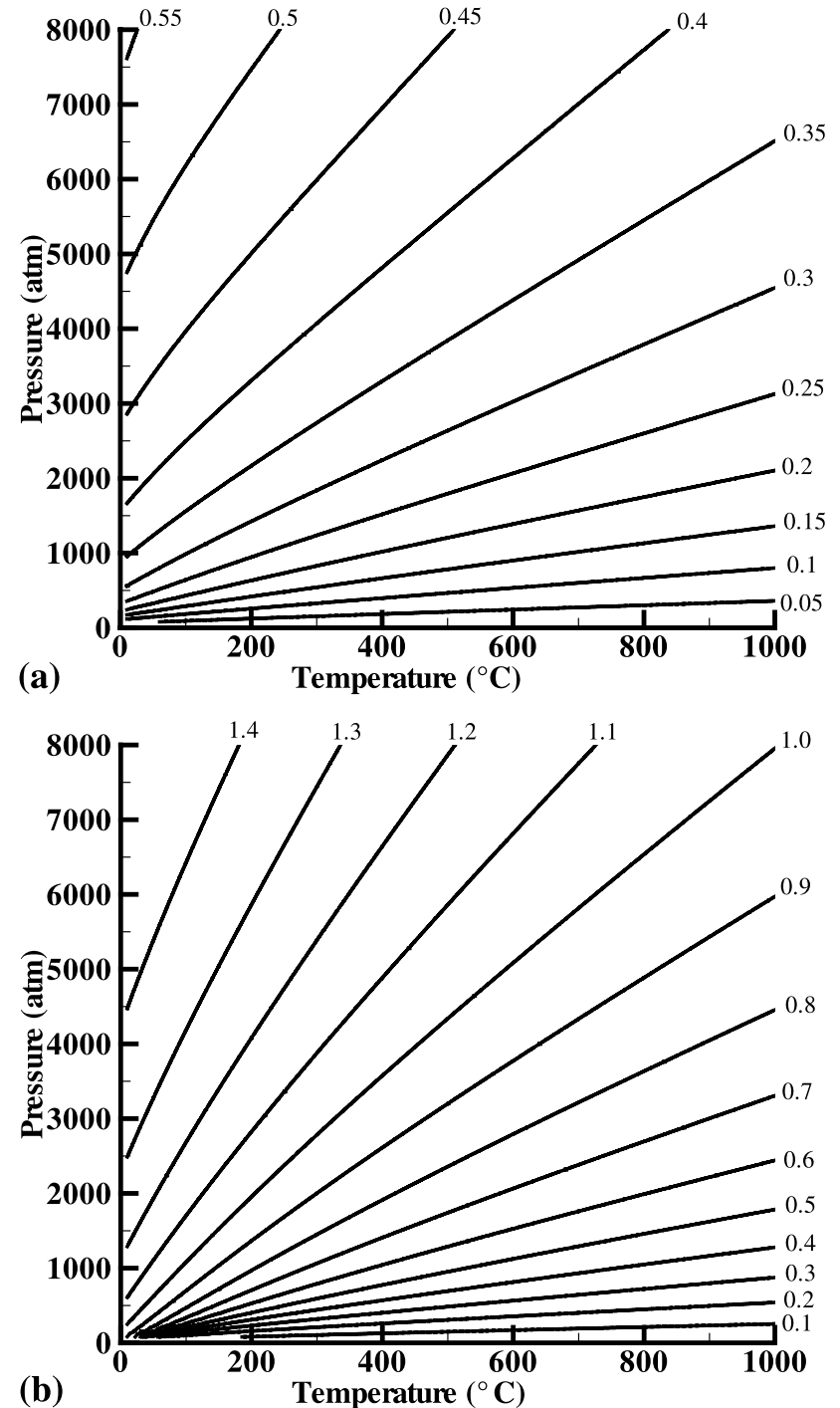

Fig. 1. Calculated density $\left(\mathrm{g} \mathrm{cm}^{-3}\right)$ for (a) $\mathrm{CH}_{4}$ and (b) $\mathrm{CO}_{2}$ gases as a function of temperature and pressure, computed from the equation-of-state model of Duan et al. (1992).

The estimated solution with the correction at the next iteration step $q^{+1}$ is

$$
V_{\mathrm{r}}^{q+1}=V_{\mathrm{r}}^{q}+\Delta V_{\mathrm{r}}^{q}
$$

The iteration continues until the residual is within a small tolerance. Once the iteration process locates a real root $V_{\mathrm{r}}$, the molar volume $V$ can be calculated by

$$
\frac{P V}{R T}=\frac{P_{\mathrm{r}} V_{\mathrm{r}}}{T_{\mathrm{r}}}
$$

Finally, the density of gas at various P-T conditions is given by

$$
\rho=\frac{m m}{V}
$$

where $m m$ is the molar mass (the number of grams in one mole of a substance) of gas. Figure 1 shows the calculated density of $\mathrm{CH}_{4}$ and $\mathrm{CO}_{2}$ gases as a function of temperature and pressure. According to the EOS model, gas density decreases with increasing temperature but increases with increasing pressure. 
The density of $\mathrm{CH}_{4}$ gas is generally less than that of $\mathrm{CO}_{2}$ under the same T-P conditions. The density of gas is less than that of liquid oil in sedimentary environments, thus oil-gas conversion could cause a shortage of pore space, which, in turn, leads to pore pressure increases. For instance, if liquid oil has a density of $0.90 \mathrm{~g} \mathrm{~cm}^{-3}$ and the generated gas has a density of $0.45 \mathrm{~g} \mathrm{~cm}^{-3}$, then there is an approximately $50 \%$ increase in volume. The equation of state provides a smooth and accurate calculation of gas density in the range of temperature and pressure of interest.

\section{NUMERICAL CASE STUDIES}

Geopressuring from compaction and hydrocarbon generation

A 1-D transient model is used to demonstrate how disequilibrium compaction and hydrocarbon generation act together to generate overpressure with time. The numerical models simulate the deposition and compaction of a $10 \mathrm{~km}$ thick shale at a uniform rate of $1 \mathrm{~mm} \mathrm{a}^{-1}$ over a period of $10 \mathrm{Ma}$. The permeability of shale is set to $10^{-6} \mathrm{D}$. The pre-exponential factor $A_{\mathrm{o}}$ and the activation energy $E_{\mathrm{o}}$ of oil generation in the shale are set to $6.15 \times 10^{16} \mathrm{~h}^{-1}$ and $218 \mathrm{KJ} \mathrm{mol}^{-1}$, respectively, similar to those of the Devonian Woodford Shale (Lewan 1985), a significant source of oil in the Permian Basin. The basal heat flow conducted into the sediment pile is set to a constant value of $1 \mathrm{HFU}$ (or $10^{-6} \mathrm{cal} \mathrm{cm}^{-2} \mathrm{~s}^{-1}$ ). The values of $A_{\mathrm{g}}$ and $E_{\mathrm{g}}$ of gas generation are set arbitrarily to $4 \times 10^{9} \mathrm{~h}^{-1}$ and $200 \mathrm{KJ} \mathrm{mol}^{-1}$, respectively. As the shale is deposited, new sediments add load on the underlying strata, causing the shale to compact. Because shale is too impermeable to allow fluid to be expelled rapidly enough to allow normal compaction, pressures in the shale develop significantly in excess of hydrostatic. Figure $2 \mathrm{a}$ shows how the calculated oil and $\mathrm{CH}_{4}$ gas generation (as a volume fraction of capacity) at the deepest nodal point in the shale evolves through time. The deepest source beds generated oil between $6 \mathrm{Ma}$ and $7 \mathrm{Ma}$ and subsequently reached the gas window between $5 \mathrm{Ma}$ and $4 \mathrm{Ma}$. Simulations show that overpressures increase significantly during oil and gas generation. Oil and gas generation together can cause excess pressure up to about $40 \%$ of that generated by compaction only. Figure $2 \mathrm{~b}$ shows the depth range for oil $(3-4 \mathrm{~km})$ and gas $(6-7 \mathrm{~km})$ generation and corresponding overpressures at the end of sediment deposition. Overpressure increases significantly over the entire range of oil and gas windows in time (Fig. 2a) and in space (Fig. 2b).

\section{Influence of reaction kinetics on hydrocarbon generation}

Different types of organic matter are characterized by different reaction kinetics, which have a profound effect on the timing of oil and gas generation. Sensitivity analyses explored how variations in activation energy and pre-exponential factor may affect gas cracking and pressure evolution. In the first three sets of numerical experiments, the values of activation energy for oil-gas conversion are set to 165,200 and $235 \mathrm{KJ} \mathrm{mol}^{-1}$ and the pre-exponential factor is held constant at $4 \times 10^{9} \mathrm{~h}^{-1}$. Figure $3 \mathrm{a}$ shows how the calculated maturation indices (as fraction of oil or gas generation) at the deepest nodal point in the basin evolve through time, assuming various $E_{\mathrm{g}}$ values. Different values of activation energy form a broad range of gas generation window and different organic matter reaches peak gas generation at different points in geological time. Oil with a lower $E_{\mathrm{g}}$ value reaches peak generation first. The analyses also show that an increase in pre-exponential factor would create a similar effect that causes oil to reach peak gas generation earlier
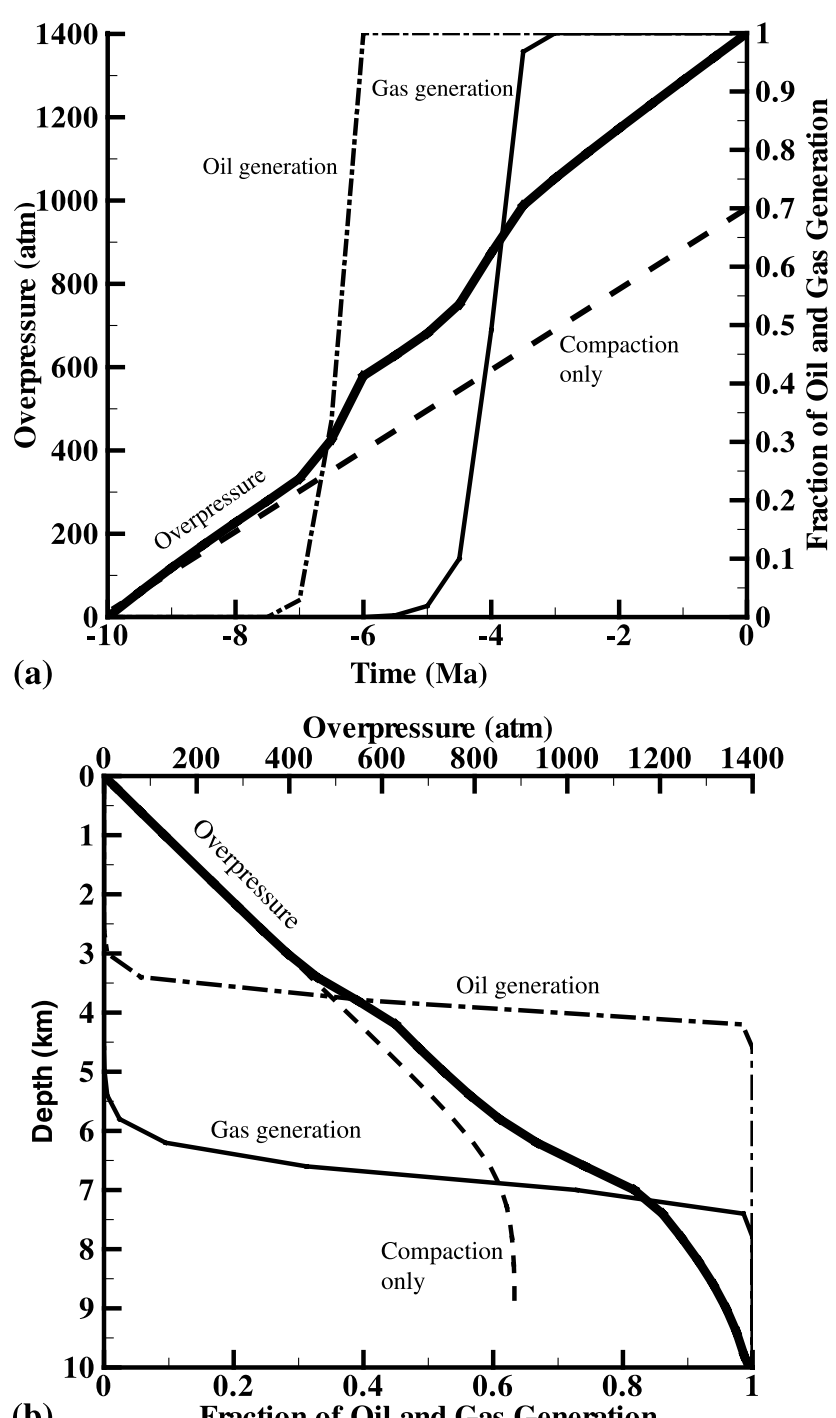

(b)

Fraction of Oil and Gas Generation

Fig. 2. (a) Calculated evolution of overpressure (thick curve) and thermal maturity at the deepest nodal point in a basin accepting continuous sedimentation of $10 \mathrm{~km}$ shale. Thermal maturation is expressed as fraction of oil generation (dash-dot curve) and gas generation (thin solid curve). (b) Overpressure and thermal maturity vs. depth profiles after deposition of $10 \mathrm{~km}$ of shale. Predicted overpressure evolution assuming compaction only is shown as a dashed line.

(Fig. 3b). The predicted duration of gas generation window could vary with the choice of kinetic parameters. Higher activation energy and lower pre-exponential factor lead to slow thermal cracking (equation (1)) that can last longer. In summary, both activation energy and pre-exponential factor could influence the timing and duration of hydrocarbon generation strongly, which, in turn, profoundly affects the 'overpressure clock'. The results stress the importance of considering oil and gas generation in evaluating the evolution of overpressure in sedimentary basins.

Influence of heat flow and sedimentation rates on overpressuring

This section considers how basal heat flow and sedimentation rates affect thermal maturation and overpressure development during the deposition of a $10 \mathrm{~km}$ thick shale over $10 \mathrm{Ma}$ (sedimentation rate of $1 \mathrm{~mm} \mathrm{a}^{-1}$ ). The simulations described in Figure 2 are repeated using different basal heat flow values of 1 , 


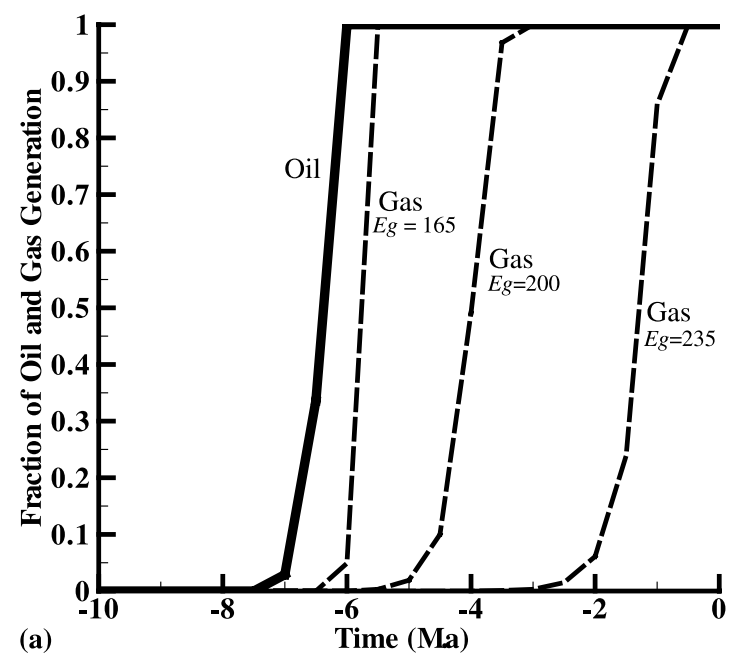

(a)

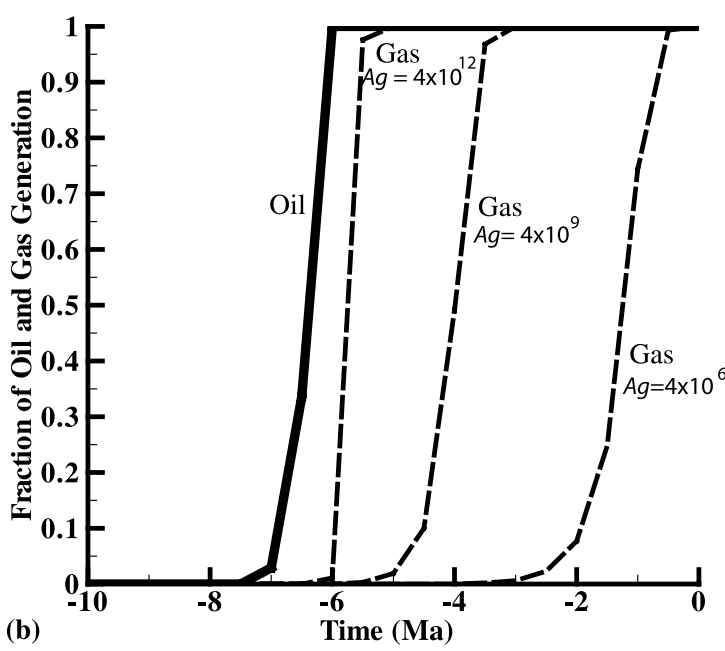

Fig. 3. Calculated evolution of thermal maturity at the deepest nodal point in a basin accepting continuous sedimentation of $10 \mathrm{~km}$ shale. Thermal maturation is expressed as fraction of oil generation (solid curve) and gas generation (dashed curves). Various dashed curves show results of runs assuming (a) different activation energy $E_{\mathrm{g}}$ and (b) different pre-exponential factor $A_{\mathrm{g}}$ for gas generation.

1.5 and 2 HFU. Figure 4 shows how the calculated maturation indices (fraction of oil and gas generation) and overpressure at the deepest nodal point evolve though time. The results show that a basin experiencing a high heat flow $(2 \mathrm{HFU})$ reaches peak oil or gas generation earlier. An earlier episode of thermal maturation also leads to higher excess pore pressures developed during the early stage of sedimentation. Interestingly, the excess pore pressures generated at the end of sedimentation are only slightly higher in the high heat flow run $(1440 \mathrm{~atm})$ than in the low heat flow run $(1400 \mathrm{~atm})$ since both systems have reached their full capacity for generating oil and gas.

The calculation for the deposition of a $10 \mathrm{~km}$ thick shale is repeated assuming different sedimentation rates of $0.1,1$ and $10 \mathrm{~mm} \mathrm{a}^{-1}$. The basin has a constant heat flow of $1 \mathrm{HFU}$ in all simulations. The predicted depth intervals of oil and gas generation are shallower at lower sedimentation rates (Fig. 5a) because sediments spend a longer time (and are thus more thermally mature) at the same depth interval. This explains why at lower sedimentation rates sediments reach higher levels of thermal maturity and exhibit greater excess pore pressure (Fig. $5 \mathrm{a}$ ) at a depth of less than $c .6 \mathrm{~km}$ (Fig. 5b). The excess pore
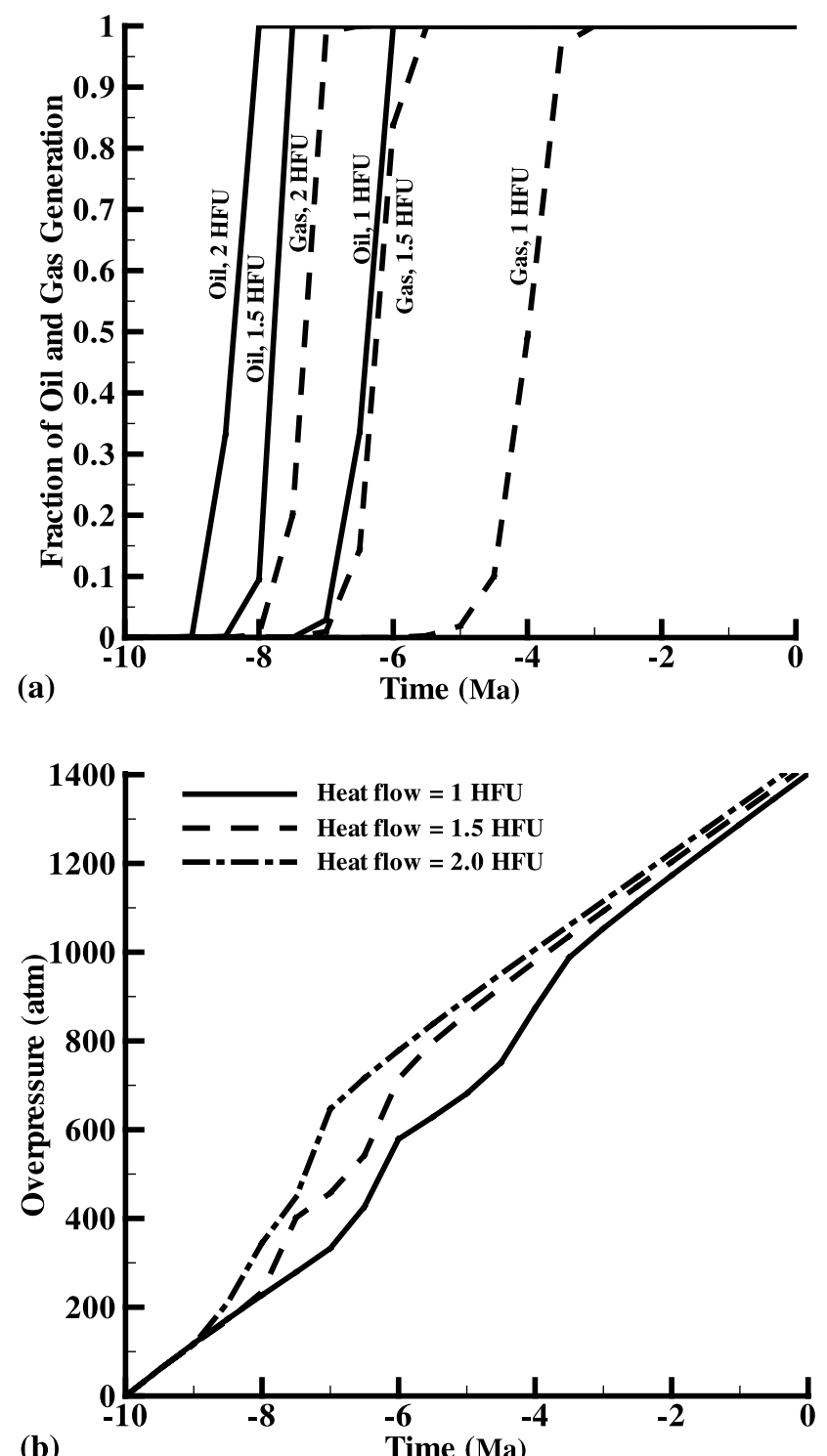

Fig. 4. Calculated evolution of oil (solid curves) and gas (dashed curves) (a) maturity and (b) overpressure at the deepest nodal point in a basin accepting continuous sedimentation of $10 \mathrm{~km}$ shale. Various curves show results of simulations assuming differing values of heat flow (1, 1.5 and $2 \mathrm{HFU})$ over time.

pressure in the basin with low sedimentation rate $\left(0.1 \mathrm{~mm} \mathrm{a}^{-1}\right)$ levels off quite noticeably at a depth $>6 \mathrm{~km}$, or near the lower limit of the calculated position of the gas window. With increasing sedimentation rates, the overpressure zone extends further downward because the oil and gas windows are positioned over the deeper section. The differing amounts of compaction observed in these simulations explain why the curves in Figure 5b extend from the surface to varying depths. At the lower sedimentation rate of $0.1 \mathrm{~mm} \mathrm{a}^{-1}$, the $10 \mathrm{~km}$ of uncompacted sediment reduces to a thickness of about $9 \mathrm{~km}$ after compaction. The same amount of sediment assumes thickness greater than $9 \mathrm{~km}$ at higher sedimentation rates of $1 \mathrm{~mm} \mathrm{a}^{-1}$ and $10 \mathrm{~mm} \mathrm{a}^{-1}$ as overpressures prevent normal compaction at greater depth. The calculation results also show that as the sedimentation rates increases from $0.1 \mathrm{~mm} \mathrm{a}^{-1}$ to $10 \mathrm{~mm} \mathrm{a}^{-1}$, the maximum overpressure at the deepest nodal point increases from about $960 \mathrm{~atm}$ to $1500 \mathrm{~atm}$. 


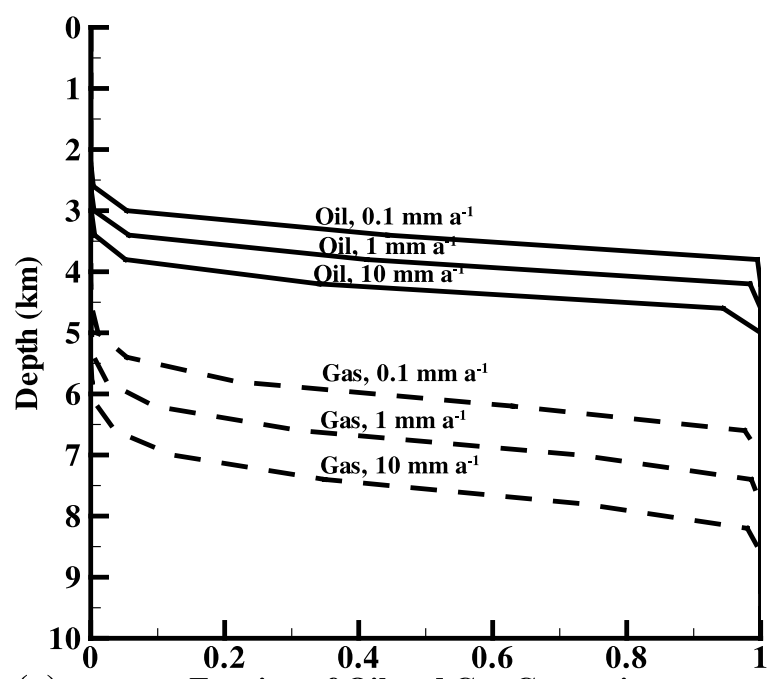

(a)

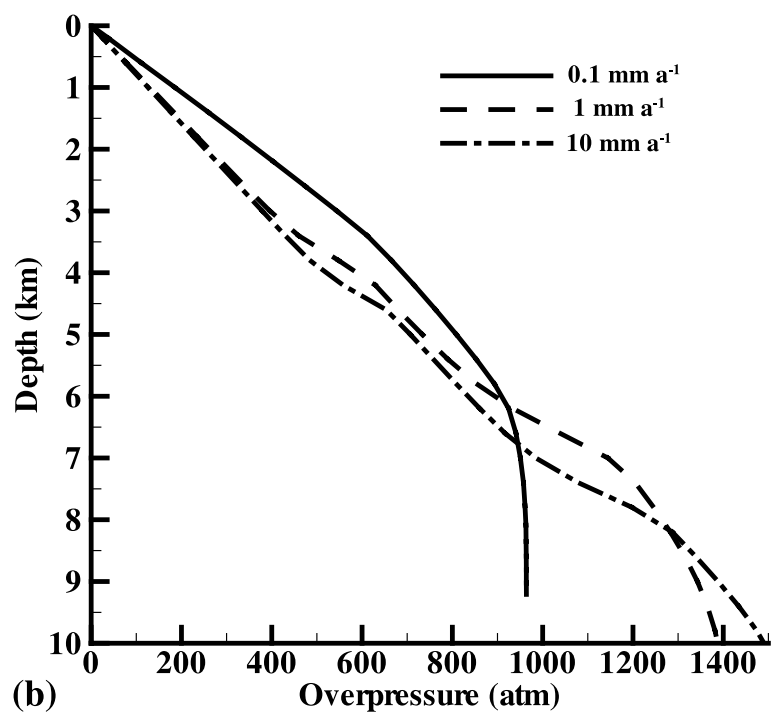

Fig. 5. Calculated profiles versus depth for oil (solid curves) and gas (dashed curves) (a) generation and (b) overpressure after deposition of $10 \mathrm{~km}$ of shale at differing rates of $0.1,1$ and $10 \mathrm{~mm} \mathrm{a}^{-1}$.
Hydrocarbon generation and overpressure development in the Permian Basin

The effects of hydrocarbon generation and sediment compaction on fluid flow and overpressure development within the Permian Basin were simulated. Data from 30 wells were used to reconstruct the hydrostratigraphy (Fig. 6) used in the simulations. The study area includes the Delaware Basin and the Central Basin Platform (CBP) and extends about 116 miles $(185 \mathrm{~km})$ across west Texas and southeastern New Mexico. The Permian Basin subsided through most of the Palaeozoic and accumulated a sedimentary succession more than $7 \mathrm{~km}$ thick. Ordovician through Mississippian strata consist mainly of thick carbonate and shale. In the Pennsylvanian, continental collision resulted in crustal block movement along high-angle faults formed earlier in the Precambrian rifting phase. This crustal block movement created two areas of subsidence and an uplifted zone within the basin (Hills 1984; Ross 1986). The uplift divided the basin into three separate provinces: the Delaware Basin to the west, the Central Basin Platform, and the Midland Basin to the east. From the Late Pennsylvanian to the Early Permian, the Delaware Basin subsided rapidly and accumulated the organic-rich Wolfcamp Shale, the major regional hydrocarbon source bed. In the Middle Permian the Delaware Basin continued to subside and accumulated a series of fine-grained siliciclastic sediments including the Brushy Canyon, Cherry Canyon and Bell Canyon units. These permeable sandstone units serve as important hydrocarbon reservoirs and carrier beds in the Permian Basin. During the Late Permian, restriction of sea-water circulation and intense evaporation resulted in the precipitation of thick layers of calcium sulphate and salt-rich Castile, Salado and Rustler evaporites. Until the latest Mesozoic the Permian Basin region experienced no significant tectonic and sedimentation activity. During the late Cretaceous to early Tertiary, the western Delaware Basin was uplifted by the Laramide orogeny. During the Oligocene, the compressional phase of the Laramide orogeny ended and basin and range extension began (Hentz \& Henry 1989; Hill 1996).

The hydrostratigraphic units of the Permian Basin in the calculations are composed of sandstones, shales, carbonates and evaporites. General hydrologic properties for each rock type, such as porosity and permeability, were assigned to

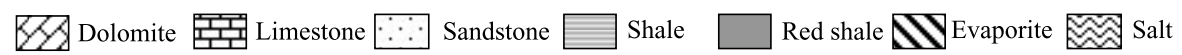

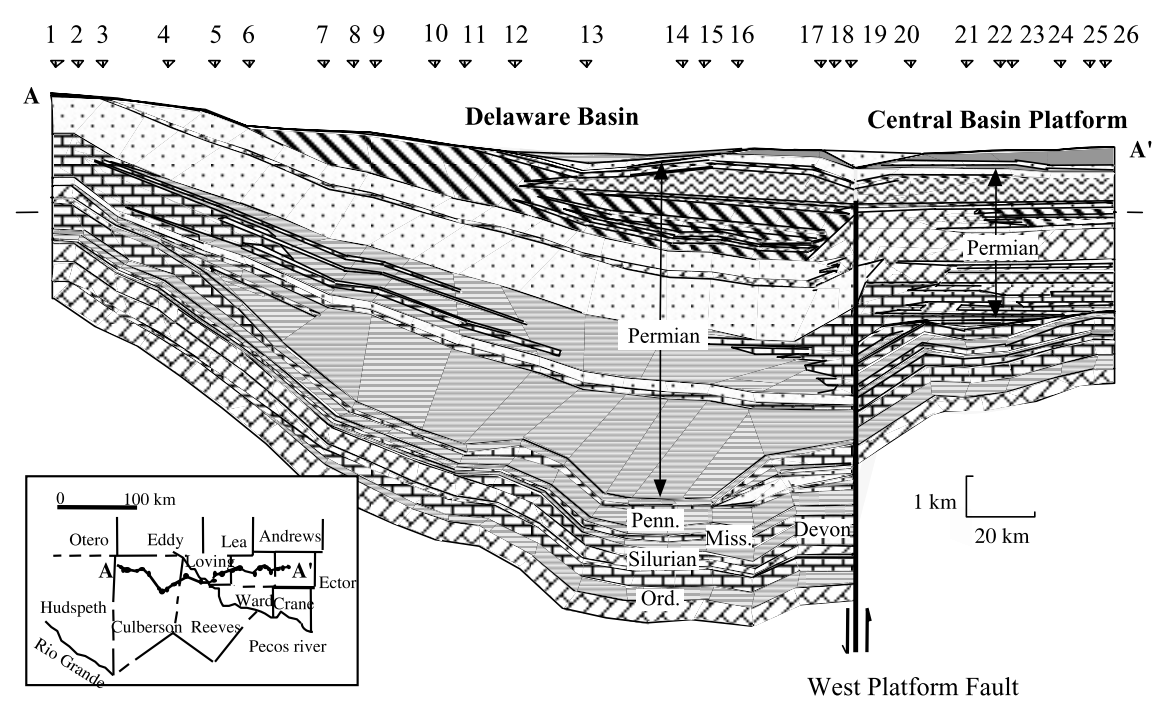

Fig. 6. Cross-section $A-A^{\prime}$ in the Delaware Basin and Central Basin Platform. Section extends about 116 miles across Culberson, Reeves, Loving, Winkler and Ector counties (modified after Matchus \& Jones 1984). 
Table 1. Correlations used in the bydrologic simulations to calculate porosity and permeability (in $\mathrm{m}^{2}$ or D)

\begin{tabular}{lcccccccc}
\hline & \multicolumn{3}{c}{ Porosity $^{\mathrm{a}}$} & & \multicolumn{3}{c}{ Permeability $^{\mathrm{b}}$} \\
\cline { 2 - 3 } \cline { 7 - 8 } & $\varphi_{0}$ & $b\left(\mathrm{~km}^{-1}\right)$ & $\varphi_{1}$ & & $\mathrm{~A}$ & $\mathrm{~B}$ & $k_{x} / k_{z}$ \\
\hline Sandstone & 0.40 & 0.50 & 0.05 & & 15 & -3 & 2.5 \\
Carbonate & 0.40 & 0.55 & 0.05 & & 6 & -4 & 2.5 \\
Shale & 0.55 & 0.85 & 0.05 & & 8 & -7 & 10 \\
Evaporite & 0.55 & 0.85 & 0.05 & & 8 & -7 & 10 \\
\hline
\end{tabular}

${ }^{\mathrm{a}} \varphi=\varphi_{0} \exp (-b Z)+\varphi_{1}$, expressed as a fraction; $Z$ is burial depth $(\mathrm{km})$.

${ }^{\mathrm{b}} \log k_{x}\left(\mathrm{~m}^{2}\right)=A \varphi+B ; k_{x} \leq 10^{-12} \mathrm{~m}^{2} ; 1 \mathrm{D} \approx 10^{-12} \mathrm{~m}^{2} . A$ and $B$ are the slope and the intercept of the correlation of permeability $k_{x}$, with porosity $\varphi$ (see Bethke et al. 1993).

represent best the transport characteristics of each strata during burial and compaction. The correlations for porosity and permeability of all rock types (Table 1) are taken from representative data from the intracratonic basins (Bethke et al. 1993). In the numerical simulations, a low-permeability $\left(10^{-11} \mathrm{D}\right)$ pressure seal overlying the Wolfcamp Shale is included to minimize the dissipation of overpressures. Luo et al. (1994) speculated that sealing capability of rocks overlying the overpressure Wolfcamp Shale may be enhanced by calcite cementation. Including such a pressure seal allows for quantification of the maximum overpressures created by dynamic processes of compaction and hydrocarbon generation. The bottom of the cross-section is set to be a no-flow boundary to reflect the low permeability Precambrian basement rocks. For all rock types, both the horizontal and vertical thermal conductivity $\left(K_{\mathrm{T}}\right.$, in cal $\mathrm{cm}^{-1} \mathrm{~s}^{-1}{ }^{\circ} \mathrm{C}^{-1}$ ) are calculated according to the following correlation to porosity

$$
K_{\mathrm{T}}=(5.35-4.4 \varphi) \times 10^{-3},
$$

which is taken from the data of Sclater \& Christie (1980) for North Sea sediments. Kinetic parameters determined for the Woodford Shale (Lewan 1985) were used to calculate the fraction of oil and gas generated through time.

Different models of the hydrologic evolution were simulated to determine the relative contributions of sediment compaction, oil and gas generation to the development of overpressure within the Permian Basin through most of the Palaeozoic. The models account for overpressure generated by (1) sediment compaction only, (2) both sediment compaction and oil generation, (3) the combined effects of compaction, oil generation and the generation of $\mathrm{CO}_{2}$ gas and (4) the combined effects of compaction, oil generation and the generation of $\mathrm{CH}_{4}$ gas.

Figure 7 shows the predicted flow field and overpressure distribution in the Delaware Basin and eastern CBP near the end of the rapid sedimentation during the late Permian. The predicted overpressures created by compaction alone reach $350 \mathrm{~atm}$ above hydrostatic near the deposition centre in the eastern Delaware Basin. The magnitude of overpressure decreases toward the basins margins along the western Delaware Basin and CBP. The large pressure gradients provide the driving mechanism for basin-wide fluid migration. The model shows that fluids drain directly from the overpressured shales into the overlying carrier beds and continuously migrate westward into the western Delaware Basin or eastward toward the CBP. Oils from reservoirs in the CBP and western Delaware Basin can be correlated geochemically to those from source beds of the overpressured shales in the eastern Delaware Basin (Hansom 2004). Such close correlations indicate long-distance fluid migration across the basin.

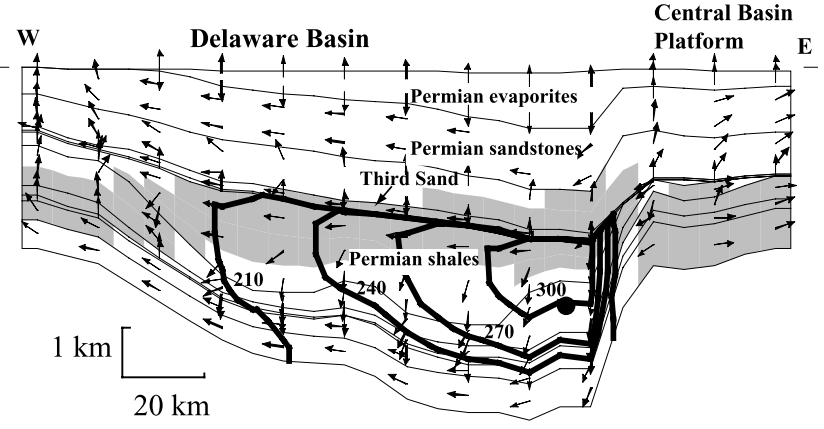

Fig. 7. Calculated groundwater flow driven by sediment compaction at the end of the Permian. Cross-section, stratigraphy and well locations are depicted in Figure 6. Contours are calculated excess pore fluid pressure (atm, above hydrostatic) in the basin. Arrows are direction-only vectors. Shaded areas map the oil window $(0.01 \leq X \leq 1)$, which shows the depth interval where oil generation can be expected according to the models if source beds are present.

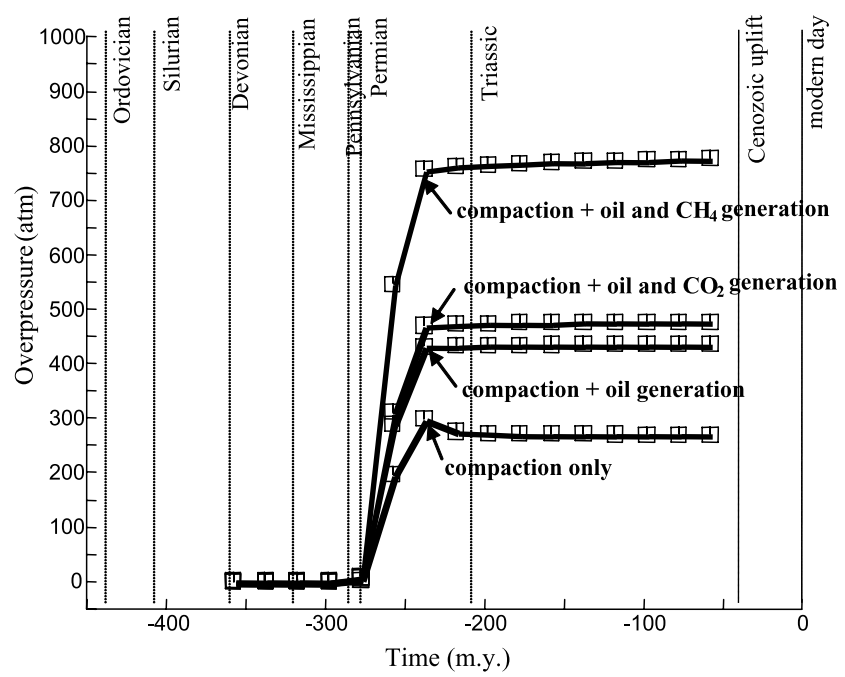

Fig. 8. Calculated overpressure evolution in the deep Delaware Basin (solid circle in Fig. 7) over time for various simulation scenarios, including (1) compaction only, (2) compaction and oil generation, (3) compaction and $\mathrm{CO}_{2}$ gas generation and (4) compaction and $\mathrm{CH}_{4}$ gas generation.

Figure 8 shows how overpressure in the deep Mississippian strata of the eastern Delaware Basin evolves through geological time, as calculated for the different scenarios of pressure generation. The timing of oil and gas generation coincides with a period of active sedimentation and temperature increases during the Permian. Simulations considering compaction only and compaction with oil generation create maximum overpressures of $300 \mathrm{~atm}$ and $425 \mathrm{~atm}$, respectively. Simulations adding $\mathrm{CO}_{2}$ and $\mathrm{CH}_{4}$ gas generation show even more pronounced increases in overpressures from the Late Pennsylvanian to the Middle Permian, up to $475 \mathrm{~atm}$ and $750 \mathrm{~atm}$, respectively. Because the density of $\mathrm{CH}_{4}$ gas is less than that of $\mathrm{CO}_{2}$ under the same $\mathrm{P}$ and $\mathrm{T}$ conditions (Fig. 1), there is greater volume increase or pore pressure build-up from oil to $\mathrm{CH}_{4}$ conversion. Hydrocarbon generation could significantly increase the magnitude of overpressure generated and extend the time period for which overpressures can be sustained or preserved. The numerical model developed in this study provides a powerful tool to evaluate quantitatively the development and preservation of overpressure in evolving sedimentary basins. 


\section{CONCLUSIONS}

Quantitative modelling of hydrocarbon generation and sediment compaction and their influence on pore pressure evolution is difficult because reliable prediction of pressure, temperature and fluid properties over a large range in evolving sedimentary basins is a considerable challenge. The integration of a basin hydrology model with the equation of state allows accurate quantification of gas density over predicted T-P range, which facilitates the assessment of the effect of thermal maturation on overpressuring. The modelling results show that overpressuring from hydrocarbon generation and sediment compaction is a transient phenomenon. The evolution of overpressuring is influenced strongly by several factors, including maturation kinetics, oil and gas type, and geological characteristics (e.g. basal heat flow, sedimentation rates, etc.). Different values of activation energy form a broad range of hydrocarbon generation windows, indicating that different organic matter reaches peak generation at different points in geological time. Lower activation energy and a higher preexponential factor lead to faster thermal cracking and an early episode of oil and gas generation.

The sensitivity analyses show that a basin experiencing a high heat flow reaches peak generation earlier, which, in turn, leads to higher excess pore pressures during its early burial history. Although the basal heat flow can control the onset or timing of the overpressure clock, it has little influence on the magnitude of excess pore pressure generated at the end of sedimentation when the source bed reaches its full capacity of hydrocarbon generation. Moreover, simulations show that, as the sedimentation rate increases, the oil and gas windows become deeper and the same amount of sediment assumes greater thickness after compaction. With increasing sedimentation rates and greater burial depths, the overpressure zone extends further downward where the oil and gas windows are positioned.

The modelling applications in the Delaware Basin show that oil and $\mathrm{CH}_{4}$ gas generation can cause excess pore pressure up to c. $40 \%$ and $110 \%$, respectively, of that generated by compaction only. Overpressure conditions in tectonically stable basins may be sustained by hydrocarbon generation over substantial periods of geological time. Numerical modelling demonstrates that hydrocarbon generation has a significant influence on the spatial and temporal distribution of overpressure in sedimentary basins.

This research was supported by grants from the AAPG Foundation (to JH) and by the Petroleum Research Fund, administered by the American Chemical Society under ASC-PRF 37071-AC2 (to M-KL). The authors would like to express their thanks to Dr Craig Bethke for providing the computer software Basin2 for new modules development.

\section{REFERENCES}

Barker, C. 1990. Calculated volume and pressure changes during the thermal cracking of oil to gas in reservoirs. AAPG Bulletin, 74, 1254-1261.

Bethke, C.M. 1986. Inverse hydrologic analysis of the distribution and origin of Gulf Coast-type geopressured zones. Journal of Geophysical Research, 91, 6536-6545.

Bethke, C.M. 1989. Modeling subsurface flow in sedimentary basins. Geologische Rundschau, 78, 129-154.

Bethke, C.M., Lee, M.-K., Quinodoz, H. \& Kreiling, W.N. 1993. Basin Modeling with Basin2, A Guide to Using Basin2, B2plot, B2video, and B2view. University of Illinois, Urbana.
Braun, R.L. \& Burnham, A.K. 1992. PMOD; a flexible model of oil and gas generation, cracking, and expulsion. Organic Geochemistry, 19, 161-172.

Bredehoeft, J.D., Wesley, J.B. \& Fouch, T.D. 1994. Simulations of the origin of fluid pressure, fracture generation, and the movement of fluids in the Uinta Basin, Utah. AAPG Bulletin, 78, 1729-1747.

Burst, J.F. 1969. Diagenesis of Gulf Coast clayed sediments and its possible relation to petroleum migration. AAPG Bulletin, 53, 73-93.

Carnahan, B., Luther, H.A. \& Wilkes, J.O. 1969. Applied Numerical Methods. Wiley, New York.

Dieckmann, H.J., Schenk, H.J., Horsfield, B. \& Welte, D.H. 1998. Kinetics of petroleum generation and cracking by programmed-temperature closedsystem pyrolysis of Toarcian Shales. Fuel, 77, 23-31.

Duan, Z., Moller, N. \& Weare, J. 1992. An equation of state for $\mathrm{CH}_{4}-\mathrm{CO}_{2}-$ $\mathrm{H}_{2} \mathrm{O}$ system: I. Pure systems from 0 to 1000 (C and 0 to 8000 bar. Geochimica Cosmochimica Acta, 56, 2605-2617.

Forbes, P.L., Ungerer, P. \& Mudford, B.S. 1992. A two-dimensional model of overpressure development and gas accumulation in Venture field, eastern Canada. AAPG Bulletin, 76, 318-338.

Ge, S. \& Garven, G. 1992. Hydromechanical modeling of tectonically driven groundwater flow with application to the Arkoma Foreland basin. Journal of Geophysical Research, 97, 9119-9144.

Hansom, J. 2004. Hydrodynamics and related biogeochemical processes in the Permian basin, west Texas. Master Thesis. Auburn University, Auburn, Alabama.

Hentz, T.F. \& Henry, C.D. 1989. Evaporite-hosted native sulfur in TransPecos Texas: Relation to late-phase Basin and Range deformation. Geology, 17, 400-403.

Hill, C.A. 1996. Geology of the Delaware Basin, Guadalupe, Apache, and Glass Mountains, New Mexico and West Texas. SEPM Publication, 96-39.

Hills, J.M. 1984. Sedimentation, tectonism, and hydrocarbon generation in Delaware Basin, west Texas and southeastern New Mexico. AAPG Bulletin, 68, 250-276.

Lee, M.-K. \& Bethke, C.M. 1994. Groundwater flow, late cementation, and petroleum accumulation in the Permian Lyons sandstone, Denver basin. AAPG Bulletin, 78, 217-237.

Lee, M.-K. \& Williams, D.D. 2000. Paleohydrology of the Delaware basin, western Texas: Overpressure development, hydrocarbon migration, and ore genesis. AAPG Bulletin, 84, 961-974.

Lee, Y. \& Deming, D. 2002. Overpressures in the Anadarko Basin, southwestern Oklahoma; static or dynamic? AAPG Bulletin, 186, 145-160.

Lewan, M.D. 1985. Evaluation of petroleum generation by hydrous pyrolysis experimentation. Philosophical Transactions of the Royal Society, 315, 123-134.

Luo, X.R. \& Vasseur, G. 1996. Geopressuring mechanism of organic matter cracking: Numerical modeling. AAPG Bulletin, 80, 856-874.

Luo, M., Baker, M.R. \& Lemone, D.V. 1994. Distribution and generation of the overpressure system, eastern Delaware basin, western Texas and southern New Mexico. AAPG Bulletin, 78, 1386-1405.

Matchus, E.J. \& Jones, T.S. 1984. East-west cross section through Permian Basin of west Texas. 1:250,000. West Texas Geological Society Publication, 84-79.

Pepper, A.S. \& Corvi, P.J. 1995. Simple kinetic models of petroleum formation; Part I. Oil and gas generation from kerogen. Marine and Petroleum Geology, 12, 291-319.

Quigley, T.M., Mackenzie, A.S. \& Gray, J.R. 1987. Kinetic theory of petroleum generation. In: Tissot, B. (ed.) Migration of Hydrocarbons in Sedimentary Basins. Collection Colloques et Seminaires - Institut Francais du Petrole, 45, 649-665.

Revil, A., Cathles, L.M. III, Shosa, J.D., Pezard, P.A. \& de Larouziere, F.D. 1998. Capillary sealing in sedimentary basins: A clear field example. Geophysical Research Letters, 25, 389-392.

Ross, C.A. 1986. Paleozoic evolution of southern margin of Permian Basin. Geological Society of America Bulletin, 97, 536-554.

Sclater, J.G. \& Christie, P.A.F. 1980. Continental stretching, an explanation of the post-mid Cretaceous subsiding of the central North Sea basin. Journal of Geophysical Research, 85, 3711-3739.

Sharp, J.M. 1983. Permeability control on aquathermal pressure. AAPG Bulletin, 67, 2057-2061.

Shi, Y. \& Wang, C. 1986. Pore pressure generation in sedimentary basins: overloading versus aquathermal. Journal of Geophysical Research, 91, 2153-2162.

Tissot, B.P., Pelet, R. \& Ungerer, P. 1987. Thermal history of sedimentary basins, maturation indices, and kinetics of oil and gas generation. $A A P G$ Bulletin, 71, 1445-1466.

Toth, J. 1962. A theory of groundwater motion in small basins in central Alberta, Canada. Journal of Geophysical Research, 67, 4375-4387.

Wolf, L.W., Lee, M.-K., Browning, S. \& Tuttle, M.P. 2005. Numerical analysis of overpressure development in the New Madrid Seismic Zone. Bulletin of Seismological Society of America, 95, 135-144. 